University of Nebraska - Lincoln

DigitalCommons@University of Nebraska - Lincoln

7-25-1994

\title{
Trends and Differentials in Mortality from Cancers of the Oral Cavity and Pharynx in the United States, 1973-1 987
}

Howard I. Goldberg

Centers for Disease Control and Prevention

Stuart A. Lockwood

Centers for Disease Control and Prevention

Stephen W. Wyatt

Centers for Disease Control and Prevention, wyatt@uky.edu

Linda S. Crossett

Centers for Disease Control and Prevention

Follow this and additional works at: https://digitalcommons.unl.edu/publichealthresources

Part of the Public Health Commons

Goldberg, Howard I.; Lockwood, Stuart A.; Wyatt, Stephen W.; and Crossett, Linda S., "Trends and Differentials in Mortality from Cancers of the Oral Cavity and Pharynx in the United States, 1973-1 987" (1994). Public Health Resources. 251.

https://digitalcommons.unl.edu/publichealthresources/251

This Article is brought to you for free and open access by the Public Health Resources at DigitalCommons@University of Nebraska - Lincoln. It has been accepted for inclusion in Public Health Resources by an authorized administrator of DigitalCommons@University of Nebraska - Lincoln. 


\title{
Trends and Differentials in Mortality from Cancers of the Oral Cavity and Pharynx in the United States, 1973-1987
}

\author{
Howard I. Goldberg, Ph.D., ${ }^{*}$ Stuart A. Lockwood, D.M.D., $\dagger$ \\ Stephen W. Wyatt, D.M.D., $\ddagger$ and Linda S. Crossett, R.D.H.†
}

Background. This analysis consisted of an examination of trends and differentials in mortality from cancers of the oral cavity and pharynx in the United States for a recent 15-year period.

Methods. The authors have used national cause-ofdeath data for the United States and intercensal population estimates to examine mortality from oral and pharyngeal cancers between 1973 and 1987 and to study differentials according to gender, race, and region of residence.

Results. The overall mortality rate from these cancers decreased by $19 \%$ during the 15 -year period, with most of the decline occurring after 1979. Mortality was much higher for men than for women and for blacks than for whites throughout the interval. Despite the overall decline, mortality rates increased among blacks, especially among black men. Mortality was highest in the South Atlantic, New England, and Mid-Atlantic states and lowest in the Mountain states.

Conclusions. The disparity between male and female mortality from oral and pharyngeal cancer stems mainly from differences in the likelihood of developing these cancers, whereas the differences between blacks and whites appears to arise more from differences in survival than in incidence. Different age patterns of mortality for blacks and whites exist, in which mortality among

From the *Division of Reproductive Health, National Center for Chronic Disease Prevention and Health Promotion, Centers for Disease Control and Prevention, Atlanta, Georgia; †Division of Oral Health, National Center for Prevention Services, Centers for Disease Control and Prevention, Atlanta, Georgia; and the $f$ Division of Cancer Prevention and Control, National Center for Chronic Disease Prevention and Health Promotion, Centers for Disease Control and Prevention, Atlanta, Georgia.

The authors acknowledge the contributions made by Lynn Ries of the National Cancer Institute's Division of Cancer Prevention and Control and Dr. Dushanka Kleinman and Dr. Philip Swango of the National Institute for Dental Research.

Address for reprints: Howard I. Goldberg, Ph.D., Division of Reproductive Health, National Center for Chronic Disease Prevention and Health Promotion, Centers for Disease Control and Prevention, MS:K35, 4770 Buford Highway, Chamblee, GA 30341.

Received March 14, 1994; accepted March 23, 1994. whites, but not among blacks, rises continuously with age. An unexplained finding ws that mortality rates were reported to have fallen in recent years, whereas incidence and survival rates have reportedly remained almost unchanged. This apparent inconsistency may have resulted from declines in the incidence of oral and pharyngeal cancers that have been masked by improved detection. Cancer 1994; 74:565-72.

Key words: oral cavity, pharynx, neoplasms, mortality.

During 1987, cancers of the oral cavity and pharynx were identified as the underlying cause of approximately 8000 deaths in the United States and were listed as a contributing cause in an additional 1700 deaths. ${ }^{1}$ Approximately 30,000 Americans annually have diagnoses of malignant lesions of the oral cavity or pharynx, making it the eighth most common type of cancer (excluding skin cancer), representing approximately $2.5 \%$ of all new cancer cases in the United States annually. ${ }^{2}$ Among males, it is the sixth most common cancer site. Relative survival rates of patients with cancers of the oral cavity and pharynx are not reported to have improved in recent years and are lower than for most other major types of cancer. Slightly more than half of patients survive at least 5 years after diagnosis. ${ }^{3} \mathrm{~A}$ recent monograph on cancers of the oral cavity and pharynx provides detailed data on levels and recent trends in mortality and incidence and survival by age and anatomical site. ${ }^{4}$

In this article, we report on trends in oral and pharyngeal cancer mortality in the United States for the period 1973-1987. We also discuss differences in oral and pharyngeal cancer mortality according to patients' age, sex, race, and state and region of residence. Finally, we examine the roots of mortality variation and decline, to determine whether they arise primarily from changing or differential incidence or from differences in survival among those with oral or pharyngeal malignancies diagnosed. 
A large proportion of these cancers are caused by modifiable behaviors. Both smoking ${ }^{5,6}$ and using smokeless ${ }^{7-9}$ tobacco have been strongly implicated as risk factors. Excessive alcohol consumption is strongly suspected of being an etiologic factor, although it is unclear whether alcohol use alone increases the risk of disease. ${ }^{5,6,10,11}$ However, there is evidence of a strong interaction between tobacco use and heavy alcohol consumption, whereby the risk of these cancers developing is far greater if both substances are used than if either is used alone. ${ }^{5,12}$ At least two studies have suggested that the use of mouthwash is a risk factor ${ }^{13,14}$ although others have revealed no such relationship. ${ }^{15-17}$ Other suggested risk factors include immunodeficiencies, various DNA viruses, Candida infections, and sunlight (lip cancer). ${ }^{18,19}$ There also are a number of suspected occupational risk factors associated with working in the wood, cotton, asphalt, shoe, printing, and forestry industries. ${ }^{20}$

Mortality associated with oral and pharyngeal cancer could be substantially reduced through improved screening, particularly of individuals at increased risk of having the disease develop. ${ }^{21,22}$ As with other forms of cancer, early detection sharply decreases the probability of dying and provides more treatment options. ${ }^{23,24}$ The delay between the onset of symptoms and diagnosis tends to be longer for these cancers than for other forms of cancer. ${ }^{25-28}$ Improved screening by dentists and, more importantly, greater awareness of and screening for oral and pharyngeal cancer by physicians could reduce mortality. ${ }^{29}$

\section{Materials and Methods}

Numerators for mortality rates presented were derived from the National Center for Health Statistics' annual cause of death files for 1973-1987. ${ }^{1}$ These files contain information on the causes of all deaths reported in the United States during each calendar year. Only the deaths in which oral or pharyngeal cancer (ICD-9-CM codes 140.0-149.9) was designated the underlying cause were included in the analysis. Denominators are based on the United States Bureau of the Census yearly intercensal estimates of population by age, sex, and race for each state.$^{30}$ Data on incidence and survival are from the Surveillance, Epidemiology, and End Results (SEER) Program sites, which cover approximately $10 \%$ of the US population. ${ }^{31}$ All rates presented are age-adjusted to the 1970 US population.

\section{Results}

During 1987 , the age-adjusted underlying mortality associated with oral and pharyngeal cancer for the United States as a whole was 2.9 deaths per 100,000 popula-
Table 1. Age-Adjusted ${ }^{*}$ Oral and Pharyngeal Cancer Mortality Rates per 100,000 Population: United States, 1973-1987

\begin{tabular}{lcc}
\hline Year & Mortality rate & $\begin{array}{c}\text { Percentage change } \\
\text { from previous year }\end{array}$ \\
\hline 1973 & 3.62 & - \\
1974 & 3.63 & +0.01 \\
1975 & 3.64 & +0.01 \\
1976 & 3.57 & -0.07 \\
1977 & 3.66 & +0.09 \\
1978 & 3.55 & -0.11 \\
1979 & 3.59 & +0.04 \\
1980 & 3.51 & -0.08 \\
1981 & 3.42 & -0.09 \\
1982 & 3.39 & -0.03 \\
1983 & 3.32 & -0.07 \\
1984 & 3.27 & -0.05 \\
1985 & 3.15 & -0.12 \\
1986 & 3.11 & -0.04 \\
1987 & 2.95 & -0.16 \\
\hline
\end{tabular}

* Age-adjusted to 1970 total U.S. population.

tion (Table 1). (If all deaths for which oral and pharyngeal cancer were contributing causes are counted, the rate rises to 3.6 per 100,000). From 1973 through 1987, mortality fell approximately $19 \%$, from 3.6 deaths per 100,000 at the beginning of the period. The rate was relatively constant from 1973 to 1979 . However, after 1979 , mortality declined steadily, by approximately 0.1 per 100,000 per year.

Although overall mortality associated with oral and pharyngeal cancer decreased considerably during the time period examined, change was not uniform throughout the population. Between 1973-1977 and 1983-1987 there was a $16.0 \%$ decline among males, whereas the rate for females decreased by only $6.3 \%$. The difference between blacks and whites was even greater with regard to change. While mortality decreased $15.9 \%$ for whites, it increased $5.3 \%$ for blacks. Mortality decreased $19.4 \%$ among white males and $7.6 \%$ among white females. It increased $9.8 \%$ among black males and $0.9 \%$ among black females (Fig. 1).

Data for the period 1983-1987 show substantial differences in mortality associated with malignancies of the oral cavity and pharyn $x$, according to sex, race, and age (Table 2). For that period, the annualized mortality was 2.7 times higher among men than among women (4.9 versus 1.8 deaths per 100,000 ). Mortality was almost twice as high among blacks as among whites (5.3 versus 2.9 deaths per 100,000 ). Among members of other races mortality was lower than for either blacks or whites. Of the race-sex categories the rate was highest by far among black males $(9.3$ deaths per 100,000$)$ and 


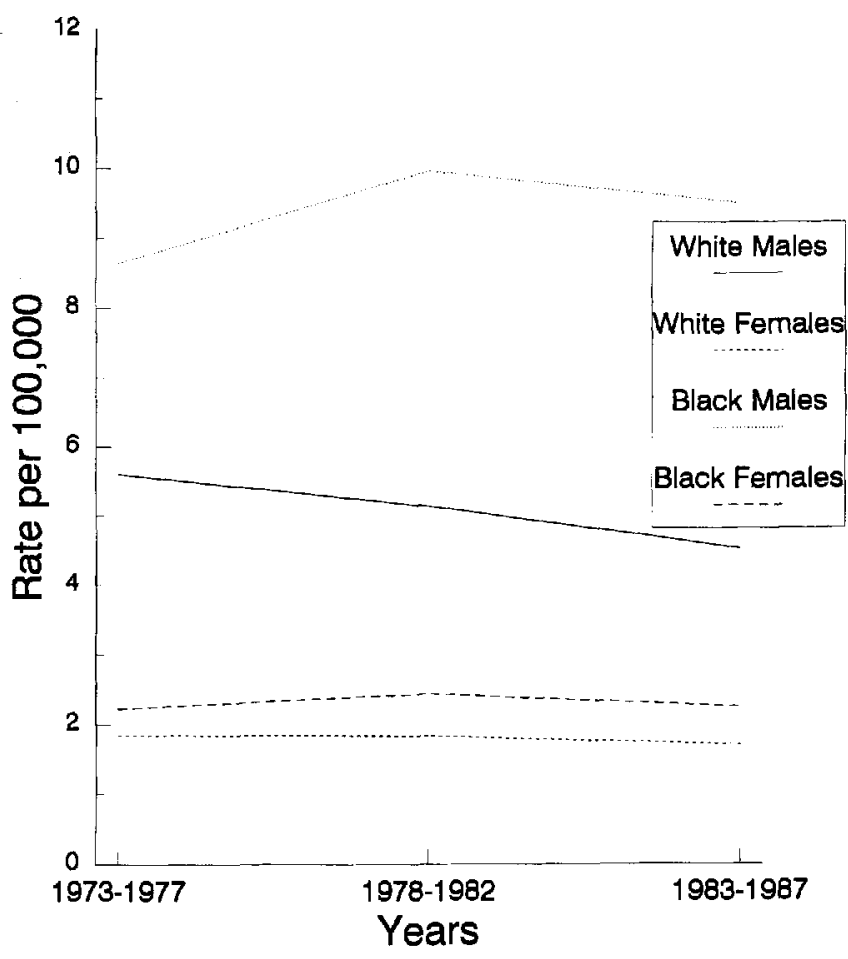

Figure 1. Age-adjusted oral cancer mortality by race and sex in the United States for the period 1973-1977 to 1983-1987.

was lowest among white females $(1.7$ per 100,000$)$ and females of other races (1.3 per 100,000). The difference between blacks and whites was much greater among males than among females.

For the overall U.S. population, oral and pharyngeal cancer mortality for 1983-1987 increased steadily with increasing age, from 0.01 deaths per year per 100,000 population for Americans younger than 15 years of age to 21.7 per 100,000 for those ages 85 years and older (Table 2). Mortality increased continuously with age among white males and females, but not among blacks (Fig. 2). Among black males, mortality decreased steadily for those in age groups older than the 55-64-year group. For black females, mortality stayed relatively constant between the age groups $55-64$ years and 75-84 years and increased for those 85 years old and older. Although overall mortality was much higher for blacks than for whites, white men and women in the oldest age groups had higher mortality than did their black counterparts. The age pattern associated with mortality for other races paralleled the pattern for whites but at a somewhat lower level.

Among white men, oral and pharyngeal cancer mortality decreased by at least $17 \%$ in every adult age group, except 25-34 years, which experienced a $15.4 \%$ increase. However, the mortality at ages 25-34 years was so low that this increase may not be meaningful. Among black men, mortality increased in every adult
Table 2. Oral and Pharyngeal Cancer Deaths and AgeAdjusted* Mortality per 100,000 Population by Sex, Race, and Age: United States, 1983-1987

\begin{tabular}{|c|c|c|}
\hline Characteristic & No. of deaths & Mortality rate \\
\hline \multicolumn{3}{|l|}{ Sex } \\
\hline Male & 27,990 & 4.9 \\
\hline Female & 13,501 & 1.8 \\
\hline \multicolumn{3}{|l|}{ Race } \\
\hline White & 34,641 & 2.9 \\
\hline Black & 6225 & 5.3 \\
\hline Other & 625 & 2.5 \\
\hline \multicolumn{3}{|l|}{ Race/sex } \\
\hline White males & 22,828 & 4.5 \\
\hline White females & 11,813 & 1.7 \\
\hline Black males & 4734 & 9.3 \\
\hline Black females & 1491 & 2.2 \\
\hline Other males & 428 & 3.6 \\
\hline Other females & 97 & 1.3 \\
\hline \multicolumn{3}{|l|}{ Age $(y r)$} \\
\hline $0-14$ & 36 & 0.0 \\
\hline $15-24$ & 124 & 0.1 \\
\hline $25-34$ & 352 & 0.2 \\
\hline $35-44$ & 1476 & 0.9 \\
\hline $45-54$ & 4954 & 4.4 \\
\hline $55-64$ & 11,721 & 10.6 \\
\hline $65-74$ & 12,634 & 14.8 \\
\hline $75-84$ & 7281 & 16.6 \\
\hline $85+$ & 2913 & 21.7 \\
\hline Total & 41,491 & 3.2 \\
\hline
\end{tabular}

age group, with the increase exceeding $9 \%$ in all but two age groups (Fig. 3). Mortality among white women declined substantially, except in the oldest age groups. There were small increases for those ages $65-74$ years and 75-84 years and a small decrease for those 85 years of age and older. Among black females, mortality de-

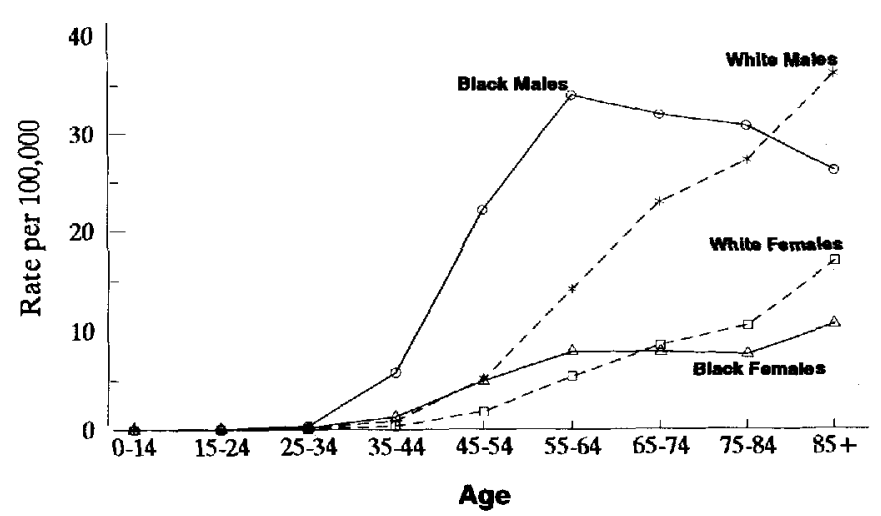

Figure 2. Oral cavity and pharyngeal cancer age-specific mortality by race and sex in the United States for the period 1983-1987. 

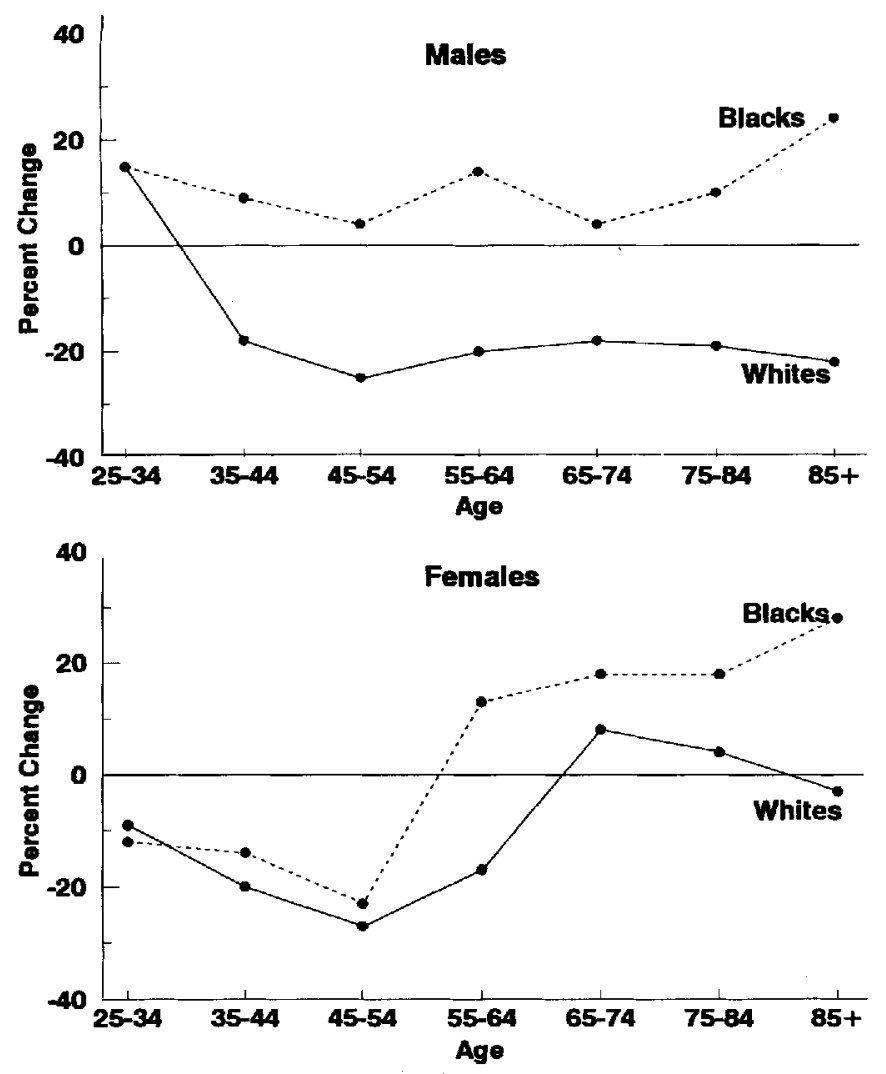

Figure 3. Percent change in oral cancer mortality by age and race in the United States for the period 1973-1977 to 1983-1987.

creased in every age group younger than 55-64 years but rose substantially for those 55-64 years and all older groups, the ages at which most oral and pharyngeal cancer mortality occurs (Fig. 3).

Mortality rates during 1983-1987 were highest in the three geographic divisions on the eastern seaboard: the South Atlantic ( 3.6 deaths per 100,000), New England (3.5 per 100,000$)$, and the Middle Atlantic (3.4 per 100,000) (Fig. 4). Rates were lowest in the Mountain states $(2.3$ per 100,000$)$ and the West North Central states $(2.5$ per 100,000$)$. Mortality declined appreciably from 1973-1977 through 1983-1987 in all nine geographic divisions of the United States, with decreases ranging from $17.7 \%$ in the West South Central states and $17.1 \%$ in New England to $8.8 \%$ in the East South Central states.

Among individual states, the mortality was highest by far in the District of Columbia (7.7 deaths per $100,000)$, followed by South Carolina (4.1 per 100,000), and Rhode Island $(4.0$ per 100,000$)$ (Fig. 5). The lowest rates were found in Utah $(1.6$ per 100,000$)$, South $\mathrm{Da}$ kota (1.8 per 100,000), and Wyoming (1.9 per 100,000$)$. Despite that the District of Columbia had the highest mortality, it experienced the greatest improvement, a decline of $36.4 \%$ from 1973-1977 through 1983-1987.
The next largest declines were recorded in Nebraska (31.6\%) and Delaware (23.9\%). Mortality associated with oral and pharyngeal malignancies increased in nine states, led by Alaska (24.0\%) and South Carolina $(17.7 \%)$.

\section{Discussion}

These results raise at least two questions that warrant discussion and closer examination. First, why are mortality patterns associated with oral and pharyngeal cancer so different between the sexes and among races? Second, what accounts for the steady decline in mortality: falling disease incidence, improved survival rates, or a combination of the two?

\section{Differences in Mortality by Sex and Race}

The available data on incidence of and mortality associated with oral and pharyngeal cancer suggest that gender and racial differences in mortality have different causes. Most of the disparity between men and women arises from differences in disease incidence, presumably stemming largely from behavioral and risk factor differences between the sexes, such as greater use of tobacco and alcohol among men. Among whites, the male/female ratio for mortality from these cancers for 1983-1987 was 2.6, the same as the ratio for incidence. In addition, 5-year survival rates for 1981-1986 were similar, $52.0 \%$ for males and $56.3 \%$ for females. Among blacks, the male/female ratios also were similar: 4.2 for mortality and 3.5 for incidence. Thus, the major difference between men and women appears to lie in whether or not they have oral or pharyngeal cancer develop. Differences in survival are relatively small, except among blacks, for whom the 5-year survival rates were $42.5 \%$ for females and $26.8 \%$ for males. With the recent narrowing of the gap between males and females in the prevalence of cigarette smoking, we might anticipate a reduction in the disparity between men and women in mortality associated with malignancies of the oral cavity and pharynx.

However, the difference in oral and pharyngeal cancer mortality patterns between blacks and whites derives more from differences in survival rates than from differences in disease incidence. The 5-year survival rate for men with cancer diagnosed between 1981 and 1986 was $52.0 \%$ among whites, but only $26.8 \%$ among blacks. For women, survival rates were $56.3 \%$ among whites and $42.5 \%$ among blacks. However, the black/white incidence ratio was only 1.5 for males and 1.1 for females. Among people ages 65 and older, the reported incidence was higher among whites than blacks. These ratios suggest that, although there clearly 


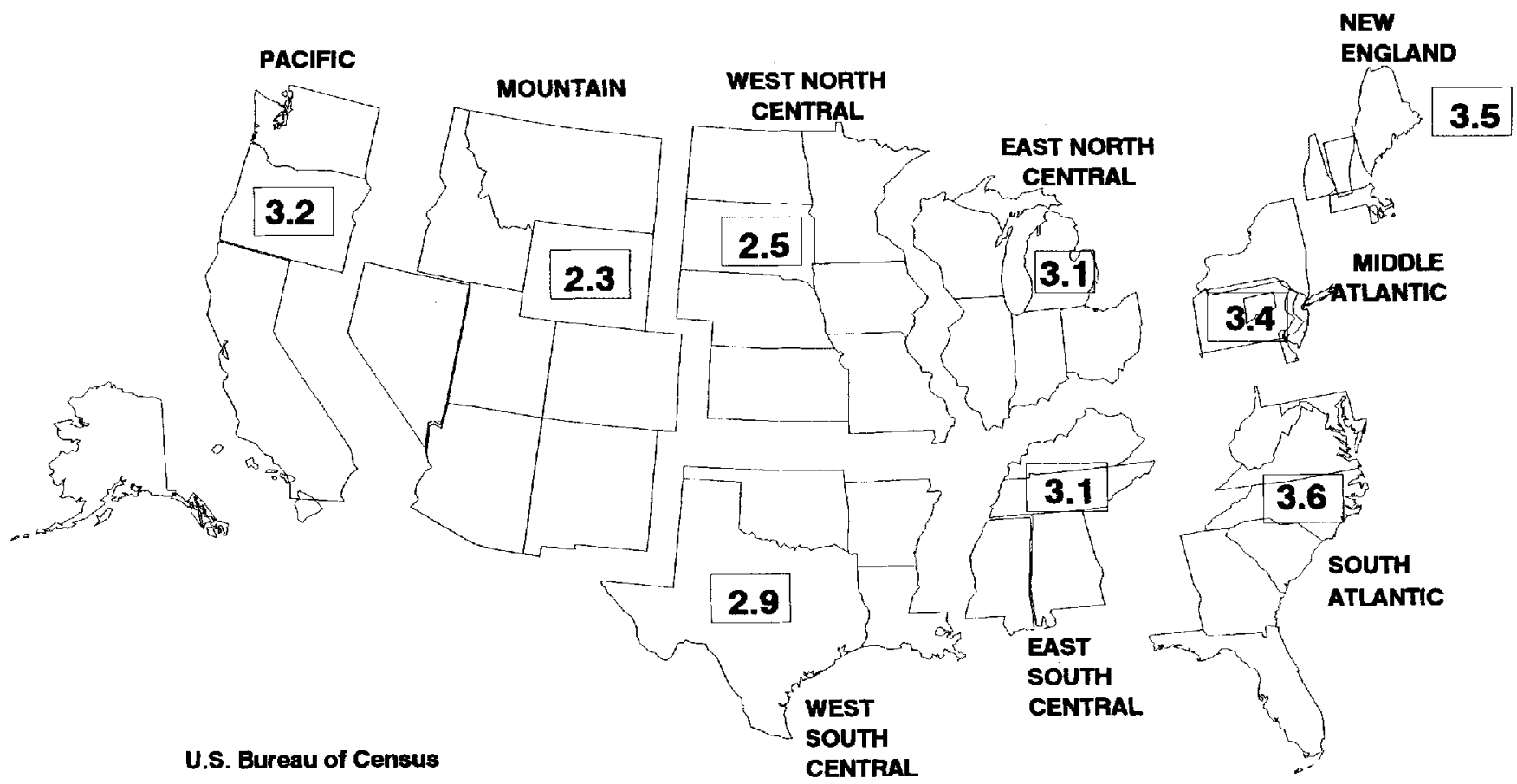

Figure 4. Oral cancer mortality age-adjusted rates per 100,000 by US geographic divisions for the period 1983-1987.

are racial differences in the likelihood of oral or pharyngeal cancer developing, differences in mortality between the races can be attributed primarily to disparities in survival probabilities.

An examination of SEER data suggests that these disparities are attributable to two factors. First, the disease tends to be diagnosed at a more advanced stage in blacks than in whites. Second, regardless of the stage at which diagnosis is made, blacks typically have shorter survival times after oral or pharyngeal cancer has been discovered. At the time of cancer diagnoses made between 1974 and 1986, lesions were twice as likely to be localized in white males as in black males $(41 \%$ versus $21 \%$ ) (Table 3). Among females, the proportion of localized lesions was $40 \%$ for whites and $27 \%$ for blacks. Likewise, oral and pharyngeal cancers were more likely to have been diagnosed in a regional or distant stage by the time of diagnosis in blacks than in whites. These figures demonstrate the need for a greater emphasis on oral and pharyngeal cancer detection activities among blacks.

As with most cancers, the stage at diagnosis of oral and pharyngeal cancer is highly correlated with the likelihood of survival..$^{21,23}$ For cancers diagnosed between 1974 and 1986, the 5-year survival rate of patients was $75 \%$ if the cancer was localized when first diagnosed, $41 \%$ if it was regionalized, and $18 \%$ if it had reached a distant site ${ }^{3}$ (Table 4 ). However, even when the stage at diagnosis is held constant, sur- vival is much greater among white men then among black men. For women, survival differences between blacks and whites are relatively small for localized and regionalized cancers and cancers diagnosed with distant metastases and nonexistent for distant site cancers.

Another noteworthy difference between blacks and whites is the age pattern associated with death from oral and pharyngeal cancer. For blacks, and particularly black men, mortality increases to its maximum at approximately age 60 years and levels. Mortality for whites continues increasing to the oldest age group. A possible explanation for these differing patterns is that members of the oldest black cohorts have had a lower risk of cancer developing than have slightly younger blacks. In such instances, cross-sectional age-specific rates would give the impression that mortality was not increasing monotonically with age. This hypothesis is supported by the age pattern associated with black mortality associated with oral and pharyngeal cancer being paralleled by the age pattern associated with incidence. ${ }^{3}$ Devesa et al..$^{31}$ compared mortality for birth cohorts and found that mortality among nonwhite men has increased considerably more rapidly for those younger than 60 years than for older groups. If the mortality pattern by age among blacks is a result of increased risk in younger cohorts, we would expect to see the pattern among blacks gradually come to resemble that of whites. 


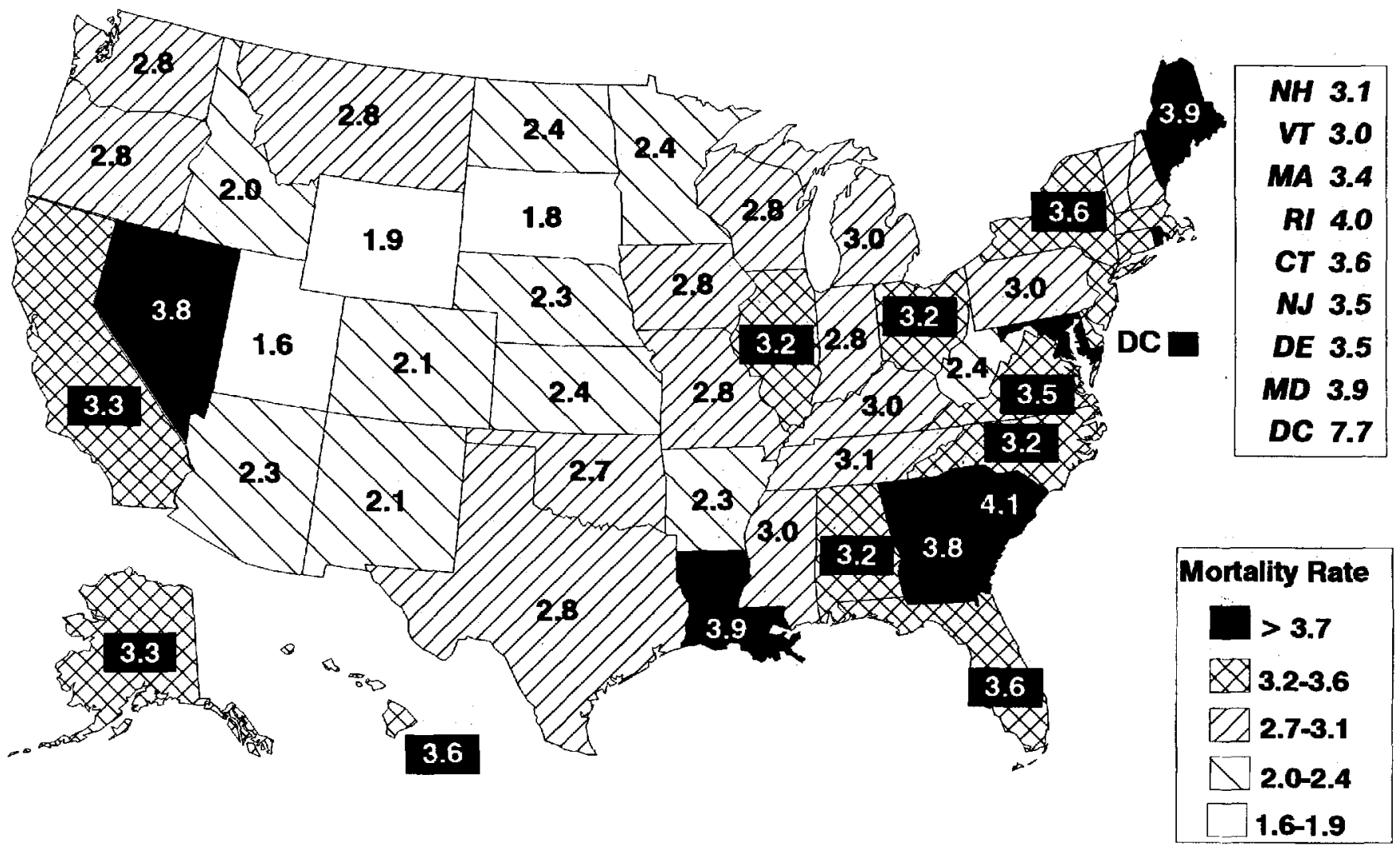

Figure 5. Oral cancer mortality age-adjusted rates per 100,000 by state for the period 1983-1987.

\section{Components of Mortality Decline}

Unfortunately, the data used in this analysis do not provide a conclusive answer to the question of what has contributed most to the mortality decline, but they do lend some insight. A closer examination of changes in

Table 3. Percentage Distribution of Stage of Oral and Pharyngeal Cancer at the Time of Diagnosis by Race and Sex, for Diagnoses Made Between 1974 and 1986*

\begin{tabular}{lccccc}
\hline & \multicolumn{5}{c}{ Stage at diagnosis } \\
\cline { 2 - 6 } Sex/race & Local & Regional & Distant & Unknown & Total \\
\hline Male & & & & & \\
Total & 38 & 40 & 12 & 9 & 100 \\
White & 41 & 38 & 11 & 10 & 100 \\
Black & 21 & 52 & 19 & 8 & 100 \\
Female & & & & & \\
Total & 39 & 41 & 11 & 9 & 100 \\
White & 40 & 40 & 10 & 10 & 100 \\
Black & 27 & 52 & 13 & 8 & 100 \\
Total & 38 & 41 & 12 & 9 & 100 \\
\hline * Cancer Statistics Review 1973-1987. National Cancer Institute 1990; Pp. IV. \\
19-IV. 36. Tables IV-13 to IV-21.
\end{tabular}

oral and pharyngeal cancer mortality reveals an apparent inconsistency between the recent downward movement in mortality and trends in incidence and survival rates. A substantial decrease in cancer mortality should be preceded by a decrease in disease incidence or an

Table 4. Five-Year Survival Rates for Individuals Diagnosed With Oral or Pharyngeal Cancer in the United States between 1974 and 1986 , by Sex, Race, and Stage at Diagnosis*

\begin{tabular}{lccccc}
\hline & \multicolumn{5}{c}{ Stage at diagnosis } \\
\cline { 2 - 6 } Sex/Race & Local & Regional & Distant & Unknown & Total \\
\hline Male & & & & & \\
Total & 75 & 39 & 16 & 44 & 50 \\
White & 77 & 40 & 16 & 46 & 53 \\
Black & 51 & 26 & 11 & 22 & 28 \\
Female & & & & & \\
Total & 76 & 46 & 24 & 47 & 55 \\
White & 76 & 47 & 23 & 47 & 56 \\
Black & 69 & 38 & 24 & 40 & 44 \\
Total & 75 & 41 & 18 & 45 & 52 \\
\hline Cancer Statistics Review 1973-1987. National Cancer Institute 1990; pp. IV. \\
19-IV. 36. Tables IV-13 to IV-21.
\end{tabular}


Table 5. Percent Change in Incidence and Mortality Rates for Oral and Pharyngeal Cancer from 1973-1977 to 1983-1987 and in Five-Year Survival Rates for Patients Diagnosed in 1974-1976 and 1981-1985

\begin{tabular}{lccc}
\hline & \multicolumn{3}{c}{ Percent change in: } \\
\cline { 2 - 4 } Sex $/$ race & Incidence* $^{*}$ & Survival * & Mortality \\
\hline White males & -4.3 & -4.1 & -19.4 \\
White females & +5.7 & +0.9 & -7.6 \\
Black males & +33.7 & -12.1 & +9.8 \\
Black females & +4.7 & -4.7 & +0.9 \\
Total & +0.6 & -3.8 & -12.8 \\
\hline
\end{tabular}

* Data from SEER program sites.

$\dagger$ NCHS public use tape.

increase in probabilities of survival. However, despite that mortality associated with oral and pharyngeal malignancies reportedly decreased by $19 \%$ nationwide and $16 \%$ in SEER Program sites between 1973 and 1987, no improvement in incidence or survival was noted for these sites. This was the only major type of cancer for which a substantial decline in mortality was not accompanied by corresponding improvements in incidence or survival. ${ }^{3}$

The reported incidence of oral and pharyngeal cancer for SEER Program sites remained virtually unchanged, at 11.3 cases per 100,000 population per year during both 1973-1977 and 1983-1987. Likewise, recent data reveal no improvement in survival rates for individuals with these cancers diagnosed. The proportions surviving for at least 5 years actually decreased from $52.9 \%$ for diagnoses made from 1974 to 1976 to $50.9 \%$ for diagnoses made from 1981 to 1986 . Even if survival for periods shorter than 5 years is examined, there is no indication of improvement. For instance, the 3 -year survival rate fell from $62.2 \%$ for diagnoses made in $1974-1976$ to $61.2 \%$ for diagnoses made during 1984-1986. The 1-year survival rate decreased from $80.2 \%$ to $79.6 \%$. Table 5 reveals that in all race-gender categories, mortality declined substantially more (or in the case of black males and females increased substantially less) than expected, given the reported changes in incidence and survival. The inconsistency persists even within age groups for each race-gender category.

It seems safe to assume that oral and pharyngeal cancer mortality did decrease substantially during the period in question. There is no reason to believe that these cancers were overreported as a cause of death in earlier years or that physicians increasingly failed to note their presence as a cause of death in more recent years. The reported decline in mortality has been steady and pervasive and is reflected in national and SEER data. Thus, it seems that incidence or survival must have improved, despite the failure of SEER statistics to reflect such improvement.

It is conceivable that a decline in incidence has been masked by improved or earlier detection of oral and pharyngeal cancer in recent years. Although there has been no decrease in oral and pharyngeal cancer incidence at SEER centers, a Connecticut study revealed a substantial decline in the incidence of these cancers among males since the early $1970 \mathrm{~s}^{32}$ Unfortunately, we cannot say with certainty that improved detection is responsible for the observed inconsistency. One generally would expect to note improvements in survival as a result of improved early detection. However, as mentioned, there was no increase in observed survival rates.

Knowing the extent to which mortality change is tied to changes in incidence or in survival rates is important in that it is an indicator of the degree to which mortality is being affected by behavioral and exposure changes (incidence) as opposed to detection and treatment changes (survival). White males are the only sexrace group to have registered a decline in incidence, and this group also has the greatest decline in smoking in recent years. If incidence has fallen but survival has not, it could be concluded that recent changes have occurred primarily because of a reduction in behaviors and exposures that can cause oral and pharyngeal cancer and not because cancers are being detected earlier and treated more effectively.

\section{References}

1. National Center for Health Statistics. Vital statistics mortality data, multiple cause of death detail, 1987 (machine-readable public-use data tape). Hyattsville, Maryland: US Department of Health and Human Services, Public Health service, CDC, 1990.

2. American Cancer Society. Cancer facts and figures-1993. Atlanta: 1993.

3. Miller BA, Ries LAG, Hankey BF, Kosary CL, Harras A, Devesa SS, et al., editors. SEER cancer statistics review, 1973-1990. (NIH publication no. 93-2789). Bethesda, Maryland: US Department of Health and Human Services, National Institutes of Health, 1993

4. US Department of Health and Human Services. Cancers of the oral cavity and pharynx: a statistics review monograph 19731987. Atlanta: Centers for Disease Control and National Institutes of Health, 1990 .

5. Blot WJ, McLaughlin JK, Winn DM, Austin DF, Greenberg RS, Preston-Martin, et al. Smoking and drinking in relation to oral cancer. Cancer Res 1988; 48:3282-7.

6. Talamini R, Franceschi S, Barra S, LaVecchia C. The role of alcohol in oral and pharyngeal cancer in non-smokers and of tobacco in non-drinkers. Int J Cancer 1990; 46:391-3.

7. Winn DM. Smokeless tobacco and cancer: the epidemiologic evidence. CA 1988; 38:236-43.

8. US Department of Health and Human Services. The health consequences of using smokeless tobacco: a report of the Advisory Committee to the Surgeon General. (DHHS publication no. 
(NIH) 86-2784). Bethesda, Maryland: US Department of Health and Human Services, Public Health Service, 1986.

9. Winn DM, Blot W], Shy CM, Pickle LW, Toledo A, Fraumeni JF. Snuff dipping and oral cancer among women in the southern United States. N Engl J Med 1981; 304:745-9.

10. Mashberg A, Garfinkel L, Harris $S$. Alcohol as a primary risk factor in oral squamous carcinoma. CA 1981;31:146-55.

11. Kabat GC, Wynder EL. Type of alcoholic beverage and oral cancer. Int J Cancer 1989; 43:190-4.

12. McCoy GD, Wynder EL. Etiological and preventive implications in alcohol carcinogenesis. Cancer Res 1979; 39:2844-50.

13. Wynder EL, Kabat G, Rosenberg S, Levenstein M. Oral cancer and mouthwash use. J Natl Cancer Inst 1983; 70:255-60.

14. Winn DM, Blot WJ, McLaughlin JK, Austin DF, Greenberg RS, Preston-Martin S, et al. Mouthwash use and oral conditions in the risk of oral and pharyngeal cancer. Cancer Res 1991; 51: 3044-7.

15. Kabat GC, Hebert JR, Wynder EL. Risk factors for oral cancer in women. Cancer Res 1989; 49:2803-6.

16. Blot WJ, Winn D, Fraumeni JF. Oral cancer and mouthwash. J Natl Cancer Inst 1983; 70:251-3.

17. Mashberg A, Barsa P, Grossman M. A study of the relationship between mouthwash use and oral and pharyngeal cancer. J Am Dent Assoc 1985; 110:711-4.

18. Binnie W, Scully C. Etiology. In: Smith S, Pindborg JJ, Binnie WH, editors. Oral cancer: epidemiology, etiology, and pathology. New York: Hemisphere Publishing, 1990:17-45.

19. Silverman S Jr., Shillitoe EJ. Etiology and predisposing factors. In: Silverman S Jr., editor. Oral cancer, 3rd ed. Atlanta: American Cancer Society 1989:7-39.
20. Vessey MP, Gray M, editors. Cancer risks and prevention. New York: Oxford University Press, 1985:103-6.

21. Silverman $S$ Jr. Early diagnosis of oral cancer. Cancer 1988; 62: 1796-9.

22. Silverman S Jr. Prevention, early detection and diagnosis of oral cancer. Dermatol Clin 1987; 5:675-80.

23. Mashberg A, Samit AM. Early detection, diagnosis, and management of oral and oropharyngeal cancer. CA 1988; 39:67-88.

24. Moore C. Education and oral cancer. In: Oral cancer interprofessional symposium. (DHEW publication no. (PHS) 1806). Washington, DC: Public Health Service, US Government Printing Office, 1966:89.

25. Hackett TP, Cassem NH, Raker JW. Patient delay in cancer. $N$ Engl J Med 1973; 289:14-20.

26. Mashberg A, Meyers H. Anatomical site and size of 222 early asymptomatic oral squamous cell carcinomas: a continuing prospective study of oral cancer: II. Concer 1976; 37:2149-57.

27. Cooke BED, Trapper-Jones L. Recognition of oral cancer: causes of delay. Br Dent J 1977; 142:96-8.

28. Guggenheimer J, Verbin RS, Johnson JT, Horowitz CA, Myers $\mathrm{EN}$. Factors delaying the diagnosis of oral and oropharyngeal carcinomas. Cancer 1989; 64:932-5.

29. Centers for Disease Control. Deaths from oral cavity and pharyngeal cancer-United States, 1987. MMWR 1990; 39:457-60.

30. Bureau of the Census. 1973-1987 Intercensal population estimates by race, sex, and age (machine-readable data files). Washington, DC: US Department of Commerce, Bureau of the Census.

31. Devesa SS, Blot WJ, Fraumeni JF. Cohort trends in mortality from oral, esophageal, and laryngeal cancers in the United States. Epidemiology 1990; 1:116-21.

32. Chen J, Katz RV, Krutchkoff DJ. Epidemiology of oral cancer in Connecticut, 1935 to 1985 . Cancer 1990; 65:2796-802. 